\title{
LA EDUCACIÓN FÍSICA, EL JUEGO EN EL PATIO Y EL APRENDIZAJE EN LA INFANCIA
}

Physical education, outdoor play and early childhood learning

Educação física, jogo no exterior e aprendizagem na infância

\begin{abstract}
Amália Rebolo
Instituto Superior de Estudos Interculturais e Transdisciplinares, Instituto Piaget, Campus de Almada / RECI (Research in Education and Community Intervention)

Tel. 00351 914804012. Correos electrónicos: amalia.rebolo@almada.ipiaget.pt, rebolo.amalia@gmail.com

Mariana Ascenso
\end{abstract}

Escola Superior de Educação Jean Piaget, campus de Almada. Telf.: 00351938740129. Correo electrónico: mariana_ascenso@hotmail.com

\section{Resumen}

El patio se caracteriza por ser un entorno diferente al aula, donde los niños pueden disfrutar de experiencias nuevas y diferentes. En este espacio se crean y se desarrollan las relaciones con los compañeros, a la vez que se adquieren y se mejoran otros conocimientos (sociales, cognitivos, motores).

Teniendo en cuenta el potencial del espacio de juego de la escuela como un aula para el aprendizaje de los diferentes contenidos de las áreas curriculares, retamos a una profesora del primer grado para realizar con su grupo de alumnos una serie de clases (seis) en el espacio exterior/espacio de juego y recreo de la escuela.

Este estudio tuvo como objetivos principales:

- Demostrar la importancia del juego en la promoción del aprendizaje y la superación de las dificultades en las áreas de Lengua Portuguesa, Matemáticas, Estudios Ambientales y Educación Física

- Demostrar los beneficios de llevar a cabo unas actividades lúdicas en el espacio exterior (recreativo) en relación con: el aprendizaje de Portugués, Matemáticas, Estudios Ambientales y Expresión Físico-Motora; cumplimiento de las normas; el trabajo en grupo; y la autonomía. 
Al final del proyecto, la mayoría de los niños mostró una gran evolución en diversas áreas del desarrollo.

Palabras clave: aprendizaje, juego, patio de recreo, actividad física, infancia

\begin{abstract}
The playground is characterized by a different environment from the classroom context and where children can experience new and different experiences. In this space, relationships with peers are created and developed, and knowledge (social, cognitive, motor) is simultaneously acquired and trained.

Taking into account the potentialities in the school playground as a classroom for learning contents of the different curricular areas, we challenged a teacher of the first year of schooling to perform with his class some classes (six) in outer space / play space and School playground.
\end{abstract}

The main objectives of this study were:

- prove the importance of play in promoting learning and overcoming difficulties in the areas of Portuguese language, Mathematics, Environment studies.

- prove the benefits of performing activities in a playful way in outer space (school playground) in relation to:

Portuguese language, Mathematics, Environment studies and Physical education; Compliance with rules, working in groups, autonomy.

At the end of the project most of the children presented a great evolution in the various areas of development.

Keywords: learning, play, playground, physical activity, childhood

\title{
Resumo
}

O espaço de recreio carateriza-se por ser um ambiente diferente do contexto de sala de aula e onde as crianças podem vivenciar novas e diferentes experiências. Neste espaço são criadas e desenvolvidas relações com os pares e simultaneamente são adquiridos e treinados conhecimentos (sociais, cognitivos, motores).

Tendo em conta as potencialidades no espaço de recreio escolar como sala de aula para aprendizagem de conteúdos das diferentes áreas curriculares, desafiámos uma docente do primeiro ano de escolaridade a realizar com a sua turma algumas aulas (seis) no 
espaço exterior/espaço de jogo e recreio da escola.

Este estudo teve como principais objetivos:

- demonstrar a importância do lúdico na promoção de aprendizagens e na superação de dificuldades nas áreas do Português, Matemática, Estudo do Meio;

- demonstrar os benefícios da realização das atividades de forma lúdica no espaço exterior (recreio) em relação a:

○ aprendizagens de Português, Matemática, Estudo do Meio e Expressão Físico-Motora; cumprimento de regras, trabalhar em grupo, autonomia.

No final do projeto a maioria das crianças apresentou uma grande evolução nas várias áreas de desenvolvimento.

Palavras-chave: Aprendizagem, jogo, recreio

\section{Introdução}

Durante a prática de ensino supervisionada (estágio) observámos crianças com falta de interesse em aprender. Esta observação tornou-se uma preocupação e procurámos novas estratégias de modo a despertar o interesse das crianças através de aprendizagens significativas.

As atividades lúdicas podem ser usadas como estratégias de ensino para utilizar em sala de aula sendo possível encontrar no mercado uma panóplia de jogos educativos em que se propõe que a criança brinque enquanto aprende conteúdos das mais diversas áreas curriculares.

Através da educação física é possível ensinar de forma interdisciplinar conteúdos das outras áreas do currículo. As aprendizagens em que a criança é participante ativa tornam-se mais significativas e parecem resistir mais ao esquecimento.

Tendo em conta a importância da actividade física, e em particular a actividade física realizada em ambientes de natureza e ar livre, quando as preocupações com a falta de mobilidade e autonomia da infância estão na ordem do dia, desenvolvemos um projecto interdisciplinar numa turma de $1^{\circ}$ ano de escolaridade (26 crianças de 6 anos). Através da educação física realizada no espaço de recreio da escola foram trabalhados conteúdos de Português, Matemática, Estudo do Meio e ainda as competências 
relacionais no âmbito da Formação Cívica.

\section{Importância do Recreio}

Segundo Pereira et al. (2003) a palavra recreio em Portugal tem dois significados distintos, o de tempo e o de espaço:

- tempo de recreio - pausa feita entre as atividades letivas; tempo curto a meio da manhã e depois do almoço durante o qual as crianças brincam livremente enquanto os professores aproveitam a pausa na atividade docente; os professores não interferem e as crianças tiram proveito de um tempo livre durante o qual podem criar brincadeiras e formas diferentes de interação.

- espaço de recreio - o local que as crianças utilizam durante as pausas entre atividades escolares; permite a realização de atividades espontâneas; também pode ser utilizado como sala de aula para a lecionação de conteúdos das mais diversas áreas; espaço muito utilizado nas aulas de educação física e de expressão e educação físico-motora.

Apesar do potencial do espaço de recreio como sala de aula raramente é utilizado pelos docentes não sendo aproveitado para colocar os conteúdos em contexto.

Este parece ser um desperdício de meios tendo em conta que ao longo do dia escolar o recreio é utilizado durante 30 minutos durante a manhã, e outro tanto após o almoço.

Azevedo et al. (2010) referem que as crianças passam demasiado tempo na escola, sobretudo em sala de aula. Frequentemente as crianças permanecem na escola após o horário letivo devido aos horários de trabalho dos pais. Os medos dos pais não lhes permitem deixar que os filhos vão para casa de forma autónoma e brinquem na rua. Resta às crianças o recreio - espaço e tempo onde têm oportunidade de brincar e escolher o que fazer, assim, o tempo/espaço de recreio ganha uma importância fundamental no quotidiano escolar e na vida das crianças.

De acordo com a National Association for the Education of Young Children (NAEYC, 1997), são quatro as áreas de desenvolvimento da criança que estão associados aos benefícios do recreio:

- Desenvolvimento social - a interação entre pares possibilita o desenvolvimento social através da aquisição de competências tais como a cooperação, a comunicação, a perceção do outro. 
- Desenvolvimento emocional - a vivência e troca de sentimentos promovem a aceitação do outro, à tolerância, ao autocontrolo e à gestão de conflitos;

- Desenvolvimento físico - a atividade física promove o desenvolvimento de habilidades motoras;

- Desenvolvimento cognitivo - promovido pelos comportamentos de exploração, os jogos e as interações.

A tomada de consciência politica da importância do espaço de recreio escolar na promoção de aprendizagens associadas a criatividade, improvisação, resolução de problemas no sentido do desenvolvimento integral das crianças deverá conduzir a maior investimento na qualificação do espaço diversificando as possibilidades de ação, de jogo e de aprendizagem. E parece ser possível afirmar que existe consciência política acerca da importância do recreio como espaço de educação como foi possível identificar nas Orientações Curriculares para a Educação Pré-escolar publicadas em 1997 - ao espaço exterior era atribuída a dupla função de permitir "a vivência de situações educativas intencionalmente planeadas e a realização de actividades informais" (Ministério da Educação, 1997: 39). Nas Orientações Curriculares para a Educação Pré-Escolar aprovadas em 2016 o recreio surge associado diferentes áreas do currículo sendo destacada a sua utilização em: Educação Física, Música, Português (Linguagem Oral), Matemática (em geral e em especial na Geometria). Neste documento é recomendado que o recreio seja utlizado como sala de aula no âmbito das diferentes áreas curriculares de acordo com as possibilidades que as suas características permitirem/criarem (Ministério da Educação, 2016).

Qualquer espaço de recreio pode/deve ser aproveitado pelos professores para o desenvolvimento de atividades formais das mais variadas áreas curriculares, trabalhando e desenvolvendo competências com recurso às condições oferecidas pela escola.

Em muitas salas de aula encontram-se materiais lúdicos que estimulam a aprendizagem, tais como cubos de barra, colares de contas, garrafas sensoriais, tapete sensorial, palavras cruzadas gigantes, sopa de letras reciclável, assim como jogos didáticos focados na aprendizagem da língua materna, matemática, história, geografia ou ciências entre outros. Porém, estes materiais e jogos não substituem a riqueza dos materiais que se encontram no ambiente ao ar livre, de ressaltar ainda, que mesmo que a existência de materiais ao ar livre seja escassa, os materiais associados ao espaço 
interior podem ser experimentados numa escala muito maior no espaço exterior. Ao promovermos o uso da sala de aula ao ar livre, as crianças envolvem-se nas experiencias de forma mais motivadora e entusiasta, uma vez que o espaço de brincadeira poderá passar a ter também valor educativo especialmente se conseguir aprender brincando.

Os fatores económicos prevalecem sobre as potencialidades de um bom espaço de recreio. Segundo Azevedo et al. (2010), as escolas pecam pelas escassas oportunidades que o espaço de recreio apresenta, para além da ausência de espaços verdes mais ricos onde o seu usufruto possa ser enriquecedor frequentemente o espaço livre é ocupado por pavilhões ou parques infantis.

Segundo Lopes (2006), no recreio é possível obter benefícios sociais (comunicação, partilha, cooperação, gestão de conflitos); emocionais (auto estima, desenvolvimento de personalidade); cognitivos (imaginação, criatividade, vocabulário, resolução de problemas) e motores (correr, saltar, manipular objetos). Também Harris (1991) citado por Brickman e Taylor (1996), destaca que as crianças nas suas atividades no exterior, vivem experiencias que não se reduzem somente às práticas motoras, observam, interagem, exploram e experimentam.

Rebolo Marques et al. (2005: 84) referem-se ao recreio como "tubo de ensaio" onde todo o conhecimento (emocional, social, cognitivo, motor) da escola e de casa é misturado e realmente testado. Os mesmos autores referem as diferenças fundamentais entre a sala de aula e o recreio destacando o poder de decisão da criança e a sua liberdade de escolha.

Sendo o recreio um espaço privilegiado para as crianças desenvolverem atividades espontâneas e sem uma estimulação estruturada, o adulto responsável pela supervisão deste espaço, deve manter-se atento e observador, interagindo com as crianças para enriquecer as suas atividades (Ministério da Educação, 1997). No entanto a intervenção por parte do adulto é normalmente limitada a chamadas de atenção por comportamentos inadequados ou para alertar para cuidados de segurança.

Para Hohmann e Weikart (1997), é no recreio que as crianças têm a liberdade que dentro da sala não lhes é permitida, sendo mais espontâneas e com mais oportunidades de se exprimirem. Se o recreio for utilizado como sala de aula é possível que a aprendizagem dos conteúdos seja mais próxima e de fácil compreensão.

São imensas as atividades que se podem desenvolver no exterior e em particular no 
espaço de recreio de forma aprender num novo ambiente, onde a criança é motivada, encorajada e envolvida, permite que as aprendizagens se tornem gratificantes e duradouras.

As atividades lúdicas com objetivos educativos quando realizadas no espaço de recreio, são vistas pelas crianças como mais um momento em que podem brincar, mesmo não sendo o brincar espontâneo, onde se podem divertir e aprender, num ambiente agradável e confiante.

\section{Educação Física ${ }^{1}$ no recreio}

Através do desenvolvimento de atividades ou jogos no espaço recreio, o professor trabalha diferentes competências motoras fundamentais para o desenvolvimento das crianças. Segundo o Programa Curricular do Ministério da Educação para o $1^{\circ}$ ciclo do Ensino Básico algumas delas são as:

- locomotoras, como por exemplo, saltar, rebolar, andar, correr,

- não-locomotoras, balançar, girar, fletir, levantar,

- $\quad$ manipulativas, apanhar, atirar, pontapear ou fazer saltar uma bola.

A promoção adequada de atividades e jogos será uma mais-valia para as crianças, podem ser criadas: estações para o desenvolvimento de diferentes competências; percursos de orientação; jogos de estafeta com transporte de diferentes materiais; percursos gímnicos aproveitando os espaços com relva/areia/sintético e as diferentes estruturas do recreio (naturais ou construídas). A atividade física pode ser associada aos conteúdos de outras áreas e por exemplo, para mudar de estação, terá que respondida uma questão ou realizada uma tarefa.

Wilson (2008) acredita que durante a atividade física as crianças desafiam as suas capacidades, desenvolvendo a autoconfiança. Cabe ao professor estar atento aos comportamentos das crianças, para que possa agir, no sentido do reforço positivo encorajando-as a continuar a tentar ou perante a tarefa desempenhada com sucesso.

\subsection{Expressão musical, dramática e plástica no recreio}

Ao utilizar o espaço de recreio como sala de aula permite-se: a observação direta dos matérias, estruturas, plantas e por vezes animais os quais podem ser representados pelas

\footnotetext{
${ }^{1}$ Em Portugal a área tem como nome específico no 1ำ ciclo "Educação e expressão físico-motora"
} 
crianças através da pintura, desenho, escultura; a utilização de materiais naturais em objetos artísticos (escultura, colagem, montagem); a construção de instrumentos musicais com materiais recolhidos no exterior; atribuição de funções e papéis a objetos/materiais naturais e representando histórias/dramas construídos a partir dos elementos recolhidos/observados.

\subsection{Estudo do Meio² no Recreio}

No espaço de recreio das escolas é frequente existirem elementos naturais como jardins, áreas arborizadas ou com estruturas.

O mundo natural brinda-nos com uma incrível riqueza de experiências sensoriais, permitindo a manipulação de recursos naturais como folhas, plantas, terra, pedras, etc.

Segundo Tovey, (2007), as crianças podem familiarizar-se com a natureza através da jardinagem, desempenhando um papel ativo em ações como cavar, semear, plantar, regar e colhe. As crianças tornam-se responsáveis e cooperantes com os colegas.

De acordo com White \& Stoecklin (2008), as crianças promovem a empatia com o mundo natural ao estabelecerem relações com os animais. A observação das características dos animais são frequentemente questionadas pelas crianças: o que comem?; como se movem?, entre outras, revelando-se uma área a que as crianças dão importância e demonstram curiosidade e sede de saber.

Wilson (2008) refere ainda o papel do professor no desenvolvimento do pensamento da criança. Este deverá procurar torna-los pequenos cientistas estimulando o seu espirito de investigação cientifica através do diálogo sobre aquilo que observam, experimentam e a forma como exploram os materiais da natureza, questionando-as e incentivando-as a fazer perguntas e comentários. As crianças são seres curiosos, descobridores e criadores, como refere Wilson (2008) as crianças são naturalmente curiosas e possuem um fascínio pelo mundo natural.

\subsection{Matemática no recreio}

De acordo com Dubiel (2000), a matemática quando é levada para fora da sala de aula permite verificar que esta está em todo o lado e não apenas nos manuais.

São vários os conteúdos matemáticos que se podem trabalhar no recreio escolar, desde

\footnotetext{
${ }^{2}$ Esta área do currículo do 1ำ ciclo inclui conhecimentos de história, geografia e ciências
} 
cálculos mentais, problemas matemáticos, geometria, simetria, frequência, etc. conhecer os conteúdos a ensinar, o grupo de crianças e o espaço de recreio permite ao professor planear as aulas no sentido da utilização das caraterísticas do meio para promover aprendizagens que por serem em contexto se espera sejam significativas e duradouras.

\subsection{Português no recreio}

Poderá ser aproveitado o espaço de recreio para a leitura de textos/histórias, uma vez que este espaço oferece um ambiente mais agradável, acrescentando um maior interesse à atividade da leitura. $\mathrm{O}$ ambiente natural cativa as crianças e para a maior parte delas é divertido deslocarem-se para o espaço exterior.

Para além da leitura, outra competência que poderá ser desenvolvida no espaço recreio é a da escrita. O dinamismo e os materiais presentes no espaço recreio, bem como a variedade de situações que nele ocorrem, poderão incentivar a criatividade.

\section{O jogo na Educação}

O lúdico pode ser utilizado como uma estratégia de ensino e aprendizagem. Os jogos que têm fins pedagógicos aumentam a construção do conhecimento, introduzindo propriedades do lúdico como a motivação e o prazer.

Segundo Neto (2001), jogar é uma das formas mais naturais do comportamento infantil. De acordo com Kami (s.d), o jogo pode ser definido de uma maneira global como um conjunto de atividades onde o nosso corpo se entrega, sobretudo pelo prazer da própria atividade. Para Neto (2003: 21), o jogo é visto como "um processo de dar liberdade de a criança exprimir a sua motivação intrínseca e a necessidade de explorar o seu envolvimento físico e social sem constrangimento. Esta estimulação ocasional proporcionada pela exploração de espaço exterior é fundamental na estruturação das primeiras fases do desenvolvimento humano".

Neto (2001a:195) refere diversos investigadores que escreveram sobre a importância do jogo no desenvolvimento da criança:

1) Garvey (1977) - visão do jogo como uma mais-valia pois a criança aprende a estruturar a sua linguagem;

2) Sutton-Smith (1979) - afirma que a cultura é transmitida através do jogo. O lúdico e os jogos passam de geração em geração, de adulto para criança, e de criança para criança, sendo um ciclo; 
3) Rubin, Fein \& Vanderber (1983) - sustentam que a promoção do jogo permite o desenvolvimento cognitivo em aspetos como: resolução de problemas, processos mentais, descoberta, habilidades e manipulação, capacidade verbal e de processar informação;

4) Levy (1984) - afirma que o jogo e os níveis de complexidade que este envolve, altera e provoca mudanças na diversidade das operações mentais;

5) Neto \& Piéron (1993) - asseguram que através das situações pedagógicas que utilizam o jogo como meio educativo as habilidades motoras são formadas e desenvolvidas.

Winnicott (1995), refere-se ao lúdico como uma mina de prazer, pela sua capacidade de envolver o sujeito de uma forma intensa e global, criando um ambiente de entusiasmo.

O envolvimento emocional que o lúdico proporciona faz com que as atividades apresentem um forte teor motivacional, capaz de gerar um estado de vibração e euforia nas crianças motivando-as para a realização das tarefas.

Quando se pensa em atividades lúdicas associamos por vezes o ato de brincar e jogar. Mas afinal como podemos explicar o que é brincar e jogar?

As crianças brincam desde muito cedo, inicialmente o ato é feito de uma forma um pouco intuitiva e espontânea. Neto (n.d) afirma que o ato de jogar e de brincar é das ações mais naturais durante a infância, por esse motivo, o brincar é considerado uma necessidade básica e uma experiência bastante rica e complexa.

A aprendizagem é facilitada quando as crianças se envolvem ativamente no processo ensino - aprendizagem e Bruner (1986) defende que estas aprendizagens se tornam mais rápidas caso se realizem em contextos lúdicos.

Serrão \& Carvalho (2011: 8) consideram que as atividades lúdicas em sala de aula não podem ser implementadas de forma descuidada, "é necessário que o jogo tenha um verdadeiro papel pedagógico". Estas atividades têm de ser pensadas, e planificadas de forma a alcançar os objetivos desejados.

As atividades lúdicas criam um clima de entusiasmo, é este envolvimento emocional que torna o lúdico um recurso motivacional. As crianças centralizam as suas energias, enfrentam as suas dificuldades, desenvolvem a imaginação proporcionando- 
lhes satisfação e contentamento.

Para atuar através do lúdico na Educação devemos partir de atividades que os alunos gostem e que os motivem, garantindo um ambiente cativante e gratificante, capaz de ir ao encontro das expectativas da criança, criando estímulos para que tenha um desenvolvimento completo. (Cerri, 2001).

Embora o lúdico esteja presente na educação (Araújo, 2009), nem sempre o mesmo é utilizado pois há quem defenda que a implementação de atividades lúdicas é importante para a aprendizagem das crianças e há discordantes que consideram que estas atividades são um desperdício de tempo.

Segundo Porto (2008) "a criança, quando brinca, entra num mundo de comunicações complexas que vão ser utilizadas no contexto escolar, nas simulações educativas, nos exercícios, etc." por esse motivo as atividades lúdicas não devem ser desvalorizadas e devem fazer parte da planificação docente. Sendo sujeito do processo pedagógico, no aluno é despertado o desejo do saber, a vontade de participar e a alegria da conquista. É através da planificação de atividades lúdicas "que a criança tem a oportunidade de vivenciar regras, normas, transformar, recriar, aprender de acordo com as suas necessidades, desenvolver o seu raciocínio e a sua linguagem" (Pinto \& Tavares:232).

A partir das atividades lúdicas, obtém-se educação de qualidade, respondendo às necessidades de cada indivíduo (Santos, 2011), favorecendo uma pedagogia diferenciada na medida que permite que cada criança aprenda no seu ritmo, crie hipóteses, tome decisões e compreenda que pode aprender com os seus próprios erros.

\section{O papel do educador/professor perante a brincadeira}

O envolvimento do adulto nas brincadeiras da criança não deve ser desvalorizado. É essencial que sejamos capazes de entrar no mundo das crianças, compreendendo as suas brincadeiras, pois nesse mundo iremos conseguir aprender e descobrir um universo de informações acerca das crianças ao mesmo tempo que promovemos relações pedagógicas com base na afetividade e na confiança, e assim torna-se mais fácil ensinar.

Os contatos com as crianças são essenciais para estabelecer uma relação de proximidade e confiança. Estas interações sociais entre adulto-criança e entre criançacriança visam segundo Brazelton e Greenspan (2002) criar crianças solidárias e 
afetuosas, capazes de demonstrar os seus sentimentos, refletir os seus desejos e desenvolver as suas relações sociais.

O conceito de brincar segundo Homem (2009), é interpretado pelo senso comum como um ato de passatempo, sem funções mais importantes que entreter uma criança com atividades divertidas. Esta visão é praticada também por profissionais de educação, que além de não participarem nos momentos de brincar, utilizam apenas esses momentos para descansarem ou corrigirem trabalhos.

Através da brincadeira a criança apropria-se da realidade, expressando os seus sentimentos, desejos, medos e fantasias, aprendendo sobre si mesma, sobre os outros e sobre o mundo que a rodeia. Cabe ao adulto proporcionar um ambiente tranquilo e seguro, que contenha materiais e espaços distintos que potenciem aprendizagens e brincadeiras, e que por sua vez, originam interações entre as crianças. Quando o adulto oferece estímulos para a imaginação, as crianças "ficam mais envolvidas e interessadas nas brincadeiras e também mais criativas (Gaspar, 2010: 9).

O educador/professor deverá aproximar-se das crianças de modo a observá-las, pois o educador/professor que conhece sua turma estará atento a este potencial, especialmente no brincar, e vai levá-lo em conta no seu planeamento (Moyles, 2002: 119).

\section{Investigação}

O estudo foi provocado essencialmente pelas vivências e observações durante a prática de ensino durante a qual verificámos que as professoras não utilizam o recreio como sala de aula e raramente se interessam pelo que acontece neste espaço, nos tempos de intervalo as crianças são deixadas sob supervisão de pessoal não docente que se preocupa essencialmente com os comportamentos de risco e a resolução de conflitos. No entanto a observação e a participação em algumas das brincadeiras das crianças permitiu-nos perceber a importância do que se passa e a oportunidade que pode ser a utilização do recreio como sala de aula durante o tempo letivo.

Partimos então da questão essencial:

- Será possível promover aprendizagens com recurso ao lúdico no recreio escolar?

Que nos leva a considerar dois aspetos relacionados:

- O exterior pode ser usado como sala de aula? 
- Através da educação física e do jogo é possível ensinar português, matemática, estudo do meio, educação física?

Objetivos do estudo:

1. Demonstrar a importância da educação física e do lúdico no desenvolvimento da criança;

2. Identificar mais-valia na utilização da educação física e do lúdico para superar dificuldades nas várias áreas disciplinares;

3. Demonstrar os benefícios da realização de atividades letivas no exterior nas aprendizagens relacionadas com diferentes áreas disciplinares.

\subsection{Amostra}

A amostra constituída por 26 crianças (15 crianças do género feminino e 11 crianças do género masculino) do $1^{\mathrm{o}}$ ano do ensino básico, de escola privada situada no concelho de Almada (Setúbal), com idades compreendidas entre os 6 e 7 anos. No grupo, não há registo de qualquer criança com necessidades educativas especiais.

\subsection{Métodos e procedimentos}

\section{Métodos}

O estudo de investigação-ação, requereu observação participante e notas de campo. Inicialmente foram recolhidas informações acerca das crianças através da observação e registo. Na fase de implementação do projeto foram registadas todas as reações, efeitos, incidências que foram observadas durante e após cada uma das seis sessões de jogo/aula realizadas no espaço de recreio da escola.

Foram planificadas seis sessões de aula com utilização de atividades físicas essencialmente lúdicas no espaço de jogo e recreio escolar em tempo letivo. Em cada sessão a igualdade de oportunidades foi uma preocupação, toda a organização do processo pedagógico foi intencional e sistemática tendo sido planeado o trabalho e avaliado o processo e os efeitos no desenvolvimento e na aprendizagem das crianças.

A planificação teve em conta as dificuldades observadas em sala de aula, verificámos que através das atividades lúdicas os alunos realizaram aprendizagens de forma divertida, foi criada uma boa dinâmica no grupo mantendo o significado pedagógico, estimulando o conhecimento, a aprendizagem e o desenvolvimento. 
A avaliação foi baseada na observação naturalista; avaliação do processo/produto final e participação e interesse das crianças. A avaliação através de registos de observação foi confirmada posteriormente quando as crianças foram avaliadas em sala de aula, através de um teste formativo ou de exercícios de fichas ou do manual e constatámos que as crianças tinham menor dificuldade, desta forma comprovando que a aprendizagem através do lúdico pode ser uma aprendizagem de longo prazo.

Na tabela 1 são apresentadas as actividades/jogos realizados e identificadas as áreas de conteúdo trabalhadas. Todos os jogos implicaram a utilização e prática dos padrões fundamentais de movimento - correr, saltar e lançar - associados a tarefas específicas que permitiam trabalhar conteúdos específicos de Português, Matemática, Estudo Meio ou Expressão Dramática. Todos os jogos foram realizados em equipa promovendo a cooperação e a aceitação das diferenças entre os grupos e cada um. Foram realizados percursos com pistas e "caças a ..." (por vezes era o próprio). A preocupação com o Português e a Matemática resulta da existência de provas de aferição e exames nacionais para os quais importaria preparar as crianças de acordo com a docente titular da turma.

Tabela 1 - Atividades/jogos realizados ao longo das sessões e conteúdos trabalhados nas diferentes áreas

\begin{tabular}{|l|c|c|c|c|c|}
\hline \multirow{2}{*}{\multicolumn{1}{c|}{ ATIVIDADES/JOGOS }} & \multicolumn{5}{c|}{ ÁREAS DISCIPLINARES } \\
\cline { 2 - 6 } & $\begin{array}{c}\text { Língua } \\
\text { Portuguesa }\end{array}$ & Matemática & $\begin{array}{c}\text { Estudo do } \\
\text { Meio }\end{array}$ & $\begin{array}{c}\text { Educação } \\
\text { Física }\end{array}$ & $\begin{array}{c}\text { Expressão } \\
\text { Dramática }\end{array}$ \\
\hline Jogo da Macaca Matemática & $\mathrm{X}$ & & $\mathrm{X}$ & $\mathrm{X}$ & \\
\hline Jogo Estafetas com histórias & $\mathrm{X}$ & & $\mathrm{X}$ & $\mathrm{X}$ & \\
\hline Jogo da Memória com antónimos & $\mathrm{X}$ & & $\mathrm{X}$ & & \\
\hline Jogo Caça às contas & & $\mathrm{X}$ & & $\mathrm{X}$ & \\
\hline Formar frases com palavras soltas & $\mathrm{X}$ & & & & \\
\hline Jogo da Apanhada de contas matemáticas & & $\mathrm{X}$ & & $\mathrm{X}$ & \\
\hline Explorar o espaço exterior (pinhal), criar história & $\mathrm{X}$ & & & $\mathrm{X}$ & $\mathrm{X}$ \\
\hline A letra “J" - Caça às palavras & $\mathrm{X}$ & $\mathrm{X}$ & & $\mathrm{X}$ & \\
\hline A letra "J" - Palavras cruzadas & $\mathrm{X}$ & $\mathrm{X}$ & & $\mathrm{X}$ & \\
\hline Jogo - Sou sílaba, sou palavra & $\mathrm{X}$ & $\mathrm{X}$ & & $\mathrm{X}$ & \\
\hline Boneco Geométrico & & $\mathrm{X}$ & & & \\
\hline Problema matemático & & $\mathrm{X}$ & & & \\
\hline Tangram - Quem sou eu? & & $\mathrm{X}$ & & & \\
\hline Envelopes Mágicos & $\mathrm{X}$ & & $\mathrm{X}$ & & \\
\hline O jogo sem fim & $\mathrm{X}$ & $\mathrm{X}$ & $\mathrm{X}$ & $\mathrm{X}$ & $\mathrm{X}$ \\
\hline
\end{tabular}

\subsection{Instrumentos}

Os instrumentos utilizados para a recolha de dados foram a observação e as notas de 
campo resultantes visto que "as ações podem ser melhor compreendidas quando são observadas no seu ambiente habitual de ocorrência" (Bogdan \& Biklen, 1994: 48).

Para cada sessão de atividade foi elaborada uma tabela de avaliação dos resultados obtidos junto dos alunos. Cada criança foi avaliada segundo uma escala nominal (não conseguido, em processo e conseguido), nas competências que se pretendia que cada uma desenvolvesse e atingisse no decorrer das atividades propostas. Esta avaliação teve por base os registos de observação direta e a correção de trabalhos sobre os conteúdos abordados.

\subsection{Condições de Realização}

Para a realização deste estudo, foi apresentada a proposta à direção da instituição assim como aos educadores e professores envolvidos. Foi garantida a confidencialidade dos dados em relação aos participantes.

A seleção das atividades teve em principal consideração os domínios de conteúdos presentes nos Programas de Matemática e de Português do $1^{\circ}$ ano Ensino Básico. Frequentemente foi realizado trabalho em equipa promovendo a cooperação e interajuda entre as crianças, gerindo conflitos e tomando decisões em grupo. A conciliação da área de educação e expressão físico-motora com as outras áreas visou sobretudo estimular a atenção dos alunos e proporcionar-lhes uma possibilidade de aprender com gosto através de atividades multidisciplinares que implicam atividade física, jogo e relacionam diferentes áreas. Na tabela 2 são indicados os jogos realizados em cada uma das sessões de aula com educação física e jogo realizada no espaço de recreio.

Tabela 2 - Lista de jogos realizados em cada sessão

\begin{tabular}{|c|l|}
\hline Sessão & \multicolumn{1}{c|}{ Jogos } \\
\hline 1 & $\begin{array}{l}\text { Macaca matemática - Estafeta de histórias - Jogo da memória } \\
\text { com antónimos - Caça às contas matemáticas }\end{array}$ \\
\hline 2 & $\begin{array}{l}\text { Sou palavra, agora sou frase - Apanhada de contas - Contador } \\
\text { de histórias }\end{array}$ \\
\hline 3 & Sou a letra "J" - Palavras cruzadas da história do João \\
\hline 4 & Sou sílaba, agora sou palavra - Boneco Geométrico \\
\hline 5 & Vamos ajudar o Sr. Jorge - Tangram - Envelopes Mágicos \\
\hline 6 & Jogo sem fim \\
\hline
\end{tabular}


$\mathrm{Na}$ instituição existe uma área no pinhal dedicada as ciências e conteúdos relativos ao mundo natural, no entanto, raramente é utilizada pelos educadores e docentes. Este foi um dos espaços utilizado no âmbito do projeto, as crianças recolheram objetos e criaram e contaram histórias incluindo a sua escolha, pequenas pedras passaram a ser bolas de futebol ou aviões, e paus de madeira eram barcos ou lápis mágicos.

Foram criadas atividades onde a matemática esteve presente como por exemplo na apanhada de contas, onde o objetivo era apanhar uma criança em que nas suas costas tinha colada a operação matemática que resultaria no número sorteado o que implicava a realização a operação mentalmente. Quando alguém era apanhado o grupo reunia para confirmar o resultado.

Em relação ao português foi utilizado o recreio como espaço de aprendizagem da letra "J". Depois de contar a história as crianças foram incentivadas a ajudar a personagem a encontrar palavras secretas (associadas a imagens) que incluíam a letra "J" e estavam escondidas no espaço de recreio. No final realizou-se um jogo de palavras cruzadas gigante, com as palavras que tinham descoberto.

No âmbito da comunicação oral foi realizada atividade de criação de histórias com recurso ao jogo das estafetas, com imagens da sequencia da história. No final as crianças tiveram que ordenar e criar uma história em grupo e apresentá-las aos colegas. Tal como refere Wilson (2008) para a leitura de algumas histórias o ambiente ao ar livre poderá proporcionar um contexto mais significativo na medida em que as crianças se encontram num novo ambiente que as envolve e permite adquirir mais significado.

Durante a concretização do projeto, as crianças viram as atividades como jogos e brincadeiras e a participação da professora estagiária em alguns momentos era ativa, o que lhes parecia dar uma maior confiança e conforto.

\section{Apresentação, análise e discussão de resultados}

A tabela de avaliação para cada atividade foi realizada com base nos objetivos propostos e foi preenchida no final das atividades. Para cada Planificação de Atividades foi criada uma tabela de registo de resultados onde se assinalou para cada objetivo o número de crianças que alcançou os objetivos esperados, assim como as que ainda se encontram em processo e apresentam algumas dificuldades. 
Alguns objetivos foram comuns a quase todas as sessões sendo esses os que destacamos em seguida.

No âmbito do português (figura 1) trabalhado em todas as sessões, verificamos que entre a sessão 1 e a sessão 6 vai aumentando o número de crianças de atinge completamente os objetivos propostos. São exceção os objetivos: "apropria-se de novos vocábulos", na ultima sessão parecem surgir maiores dificuldades; "associa palavras ao seu significado", na penúltima sessão se verifica que mais crianças têm dificuldades em atingir mas que na ultima sessão quase a totalidade da turma consegue superar.

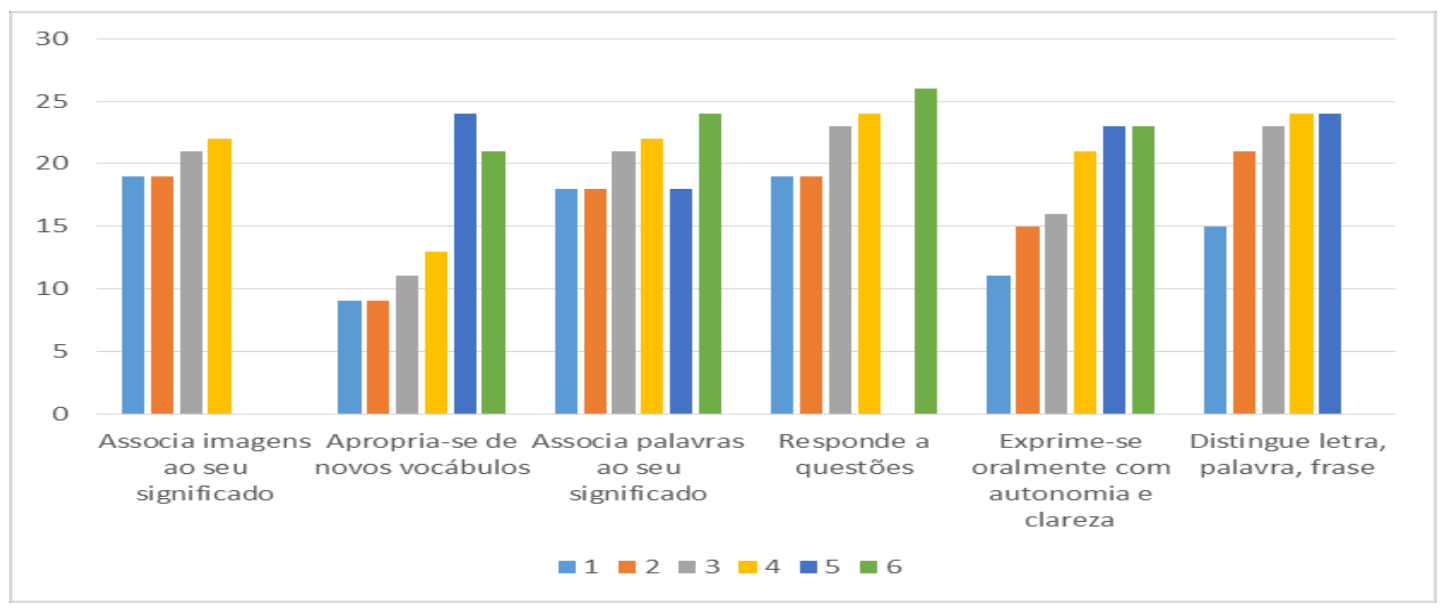

Figura 1 -Crianças que atingem na totalidade os objetivos propostos para português

Em relação à Matemática, foram realizadas atividades em quatro das sessões tendo em conta diferentes temáticas. Verificamos que de sessão para sessão aumenta o número de crianças que atinge na totalidade os dois objetivos que foram comuns a todas as sessões (figura 2).

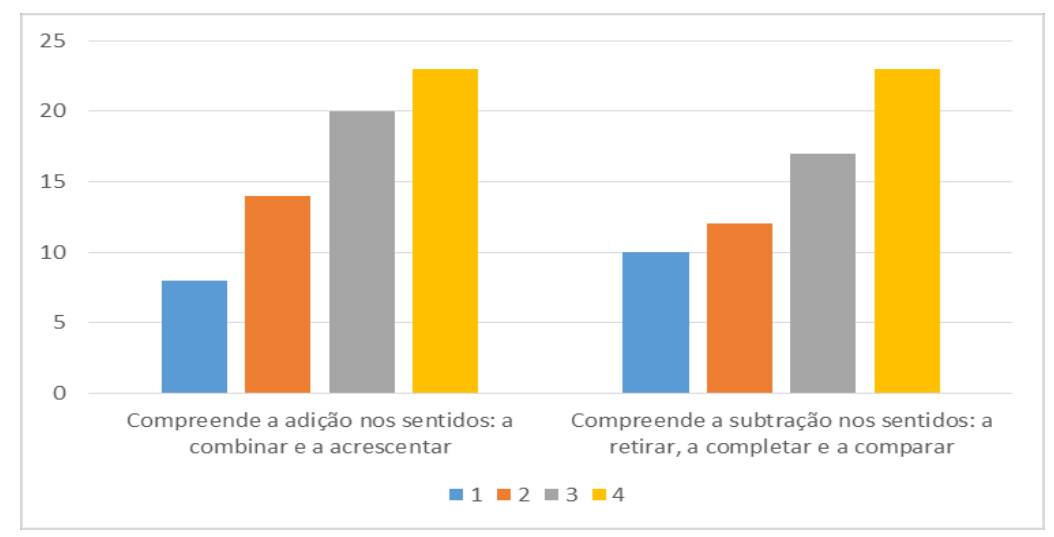

Figura 2 - Crianças que atingem na totalidade os objetivos propostos para matemática

$\mathrm{Na}$ área da Educação Física (figura 3) verificamos que existe progressão na 
realização das ações motoras básicas - correr, saltar e manipular objetos - mas verificam-se algumas dificuldades na agilidade e em relação à lateralidade. Consideramos que as dificuldades se relacionaram com o aumento de complexidade das tarefas

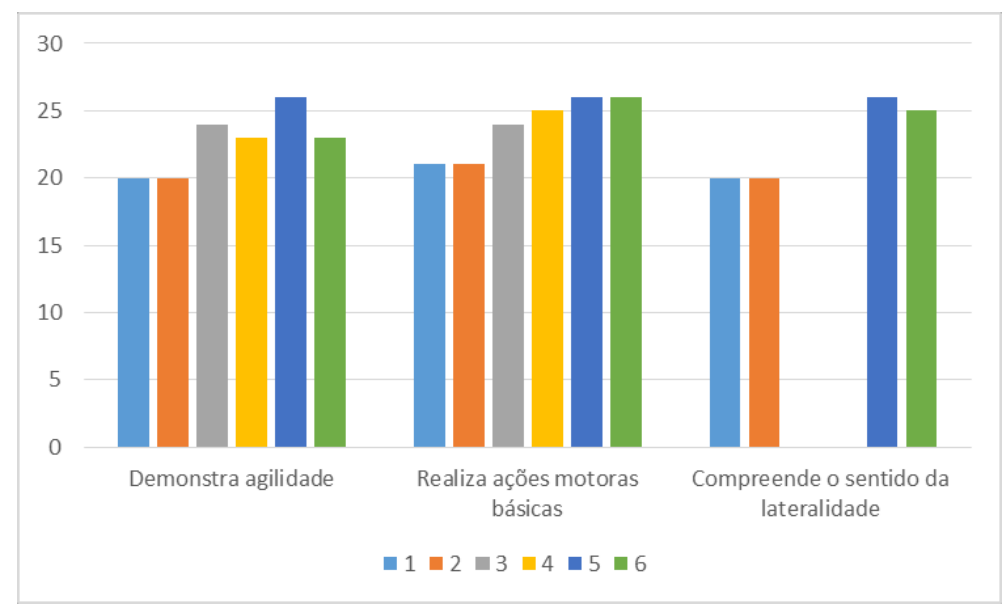

Figura 3 - Crianças que atingem na totalidade os objetivos propostos para a educação fisica

Foram ainda avaliados em todas as sessões alguns comportamentos relacionados com o trabalho em grupo, autonomia e participação. Verificamos que inicialmente existem muitas dificuldades no trabalho em grupo e também na autonomia sendo que menos de $50 \%$ das crianças consegue atingir os objetivos, no entanto são desde o início crianças que parecem respeitar as regras de participação (figura 4). Este é um aspeto que nos faz questionar o modelo de ensino expositivo tão comum nas nossas escolas em que a criança é ouvinte quieta e cumpridora das regras, mas não é estimulada a intervir, partilhar, comunicar com os outros realizar tarefas em grupo e tomar decisões. Ao longo do projeto aumenta o número de crianças que atinge os objetivos, na última sessão surgem maiores dificuldades em relação à autonomia, mas parece-nos que estão relacionadas com o aumento da complexidade do ultimo jogo. 


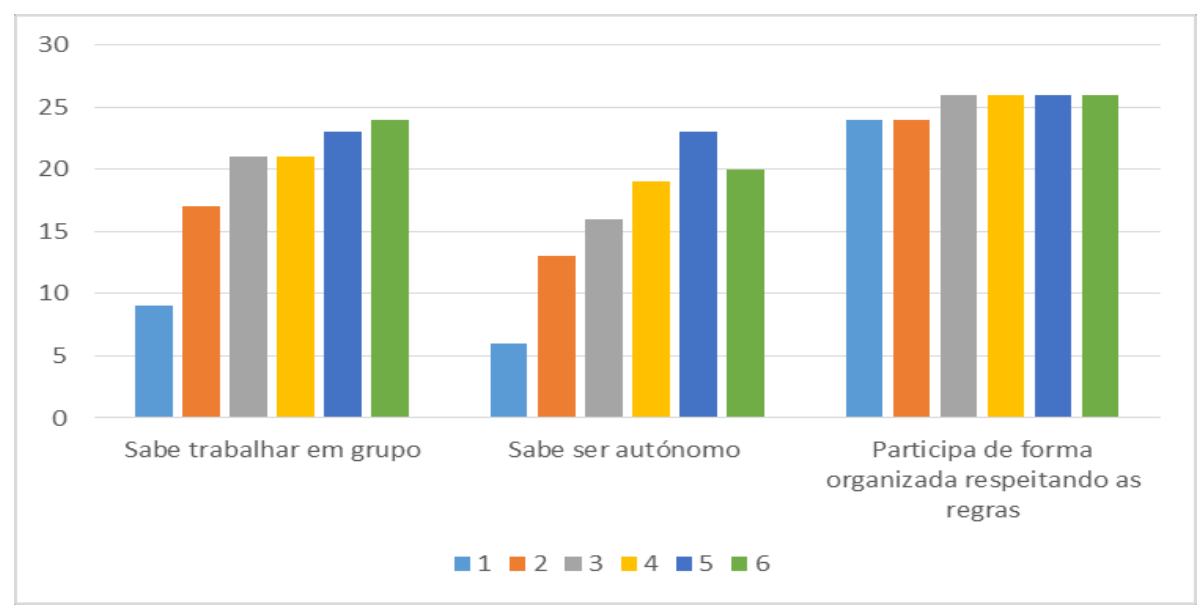

Figura 4 - Crianças que atingem na totalidade os objetivos propostos em relação ao trabalho em grupo, autonomia e participação ao longo das sessões em que foi implementado o projeto

\section{Conclusões}

Ao longo da aplicação as atividades foram encaradas pelas crianças como jogos onde se podiam divertir, enquanto foram promovidas aprendizagens em áreas específicas como o Português e a Matemática, através da experimentação foi possível perceber o abstrato a partir do concreto/vivido.

Verificámos que o número de crianças que tem sucesso no alcançar dos objetivos foi aumentando ao longo do tempo. Faltou fazer a comparação com outra turma do $1^{\circ}$ ano na mesma escola e verificar se existiam diferenças entre os níveis alcançados nas mesmas matérias, desta forma poderíamos afirmar com maior segurança que as nossas estratégias são realmente promotoras de aprendizagem a curto e a longo prazo. De qualquer modo parece-nos ser possível afirmar que o caráter lúdico das atividades e a utilização do recreio como sala de aula permitiram que as crianças aprendessem de forma contextualizada, experimentando e movendo-se.

\section{Referencias bibliográficas}

Azevedo, E., Silva, A., Lima, C., Brito, T., Pereira, B., Fernandes N. \& Coquet, E. (2010). Caraterização dos recursos dos recreios escolares. Revista Digital Buenos Aires

Bogdan, R. \& Sari Biklen. (1994). Investigação Qualitativa em Educação. Porto: Porto Editora 
Brazelton, T. B., Greenspan, S. I., (2004). A criança e o seu mundo. Requisitos iniciais para o crescimento e aprendizagem. Queluz: Editorial Presença

Brickman, N. e Taylor, L. (1996). Aprendizagem Activa. Lisboa: Fundação Calouste Gulbenkian

Bruner, J. (1986). Actual Minds, Possible Words. Cambridge: Harvard University Press.

Cardona, M. J. (2011). Educação pré-escolar ou pedagogia da educação de infância? Fundamentos e conceções subjacentes. Nuances: estudos sobre Educação, Ano XVII, v. 20, n. ${ }^{\circ} 21$, set./dez., 144-162.

Cerri. M. F. (2001). O lúdico como recurso para o professor de Educação Física atuar sobre a agressividade e a violência dos alunos nas aulas do ensino fundamental. Monografia - trabalho de conclusão de curso de Educação Física/ Instituto de Biociências, Rio Claro: Unesp.

Dubiel, M. (2000). Math Trail in Beacon Hill Park. Consulta realizada em 20 julho 2016 http://britton.disted.camosun.bc.ca/geometry/mathtrail.pdf .

Gaspar, M. F. (2010). Brincar e criar zonas de desenvolvimento próximo: A voz de Vygotsky. Cadernos de Educação de Infância, 8- 10.

Hohmann, M. e Weikart, D. (1997). Educar a Criança. Lisboa: Fundação Calouste Gulbenkian.

Homem, C. (2009). A ludoterapia e a importância do brincar: reflexões de uma educadora de infância. Cadernos de Educação de Infância (88)

Kami, C. (s.d.) A Teoria de Piaget e a Educação Pré-escolar. Lisboa: Instituto Piaget

Lopes, L. (2006). Actividade Física, Recreio Escolar e Desenvolvimento Motor. Estudos exploratórios em Crianças do $1^{\circ}$ Ciclo do Ensino Básico. Tese de Mestrado em Estudos da Criança, Especialização em Educação Física e Lazer. Universidade do Minho

Ministério da Educação. (1997). Orientações curriculares para a educação pré-escolar. Lisboa: Ministério da Educação/Departamento de Educação Básica.

Ministério da Educação/DGE. (2016). Orientações Curriculares para a Educação Préescolar. Lisboa: Ministério da Educação/Departamento de Educação Básica.

Moyles, J. (2002). Só brincar?: o papel do brincar na educação infantil. Porto Alegre: 
Artmed.

Neto, C., Pereira, B.,. \& Smith, P. (2003). Os Espaços de Recreio e a Prevenção do "Bullying" na Escola. In C. Neto (Ed.). Jogo e Desenvolvimento da Criança (pp. 238-257). Cruz Quebrada: FMH edições

Neto, C. (2001). A Motricidade e Jogo na Infância (3ª ed). Rio de Janeiro: Sprint.

Neto, C. (2001a). Aprendizagem, Desenvolvimento da Criança. Em C. Neto, Jogo \& Desenvolvimento da Criança. Lisboa: Edições: FMH-UTL

Neto, C. (n.d.) A criança e o jogo: Perspectivas de investigação. Universidade Técnica de Lisboa: Faculdade de Motricidade Humana Consultado em 20 de julho de 2016 http://www.drealg.minedu.pt/upload/docs/ea/dsapeo_pes_art 1.pdf.

NAEYC - National Association of Early Childhood Specialists in State Departments of Education (1997). The value of school recess and outdoor play. Consultado em 20 de julho de 2016

http://www.peacefulplaygrounds.com/pdf/right-to-recess/recess-importanceof-play.pdf.

http://www.naeyc.org/

Pinto, C. \& Tavares, H. (2010). Revista da Católica, Uberlândia, v. 2, n. 3, p. 226-235. $\begin{array}{llllll}\text { Consultado em } & 20 & \text { de } & \text { julho }\end{array}$ http://catolicaonline.com.br/revistadacatolica2/artigosv2n3/15-Pedagogia.pdf

Porto, C. (2008) Jogos e brincadeiras: desafios e descobertas. Brasil: Ministério da Educação: Secretaria de Educação e Distância Consultado em 20 de julho de 2016 http://tvbrasil.org.br/fotos/salto/series/165801Jogos.pdf .

Pereira, B., Neto, C. \& Smith, P. (2003). Os Espaços de Recreio e a Prevenção do "Bullying" na Escola. In C. Neto (Ed.). Jogo e Desenvolvimento da Criança (pp. 238-257). Cruz Quebrada: FMH edições

Rebolo Marques, A., Neto, C., Angulo, J. C., \& Pereira, B. (2001). Um olhar sobre o recreio, espaço de jogo, aprendizagem e alegria mas também de conflito e medo. In A. Estrela, \& J. Ferreira (Eds.). Atas do XI colóquio: Indiscipline et violence à l'ecole (pp.552-560). Lisboa: Universidade de Lisboa.

Rebolo Marques, A., Neto, C., Pereira, B. \& Angulo, J. C., (2005). Bullying no contexto escolar: jogo e estratégias de intervenção. In Cinergis, revista do departamento 
de educação física e saúde, v. 6, n. 1, jan/jun, 81-95

Santos, S. M. (2011). O Lúdico na Formação de Professores. Editora: Vozes

Serrão, M. \& Carvalho, C. (2011) O que dizem os Educadores de Infância sobre o jogo. Revista Ibero-Americana de Educação. Consultado em 20 de julho de 2016 http://www.rieoei.org/deloslectores/3824Serrao.pdf .

Tovey, H. (2007). Playing Outdoors: Spaces and Places, Risk and Challenge. London: Open University Press, Mc Graw Hill.

Winnicott, D. W. (1995). O brincar e a realidade. Rio de Janeiro: Imago.

Wilson, R. (2008). Nature and Young Children. Encouraging Creative Play and Learning in Natural Environments. London: Routledge.

White, R. \& Stoecklin, V. (2008). Nurturing Children's Biophilia: Developmentally Appropriate Environmental Education for Young Children. Collage: Resources for Early Childhood Educator. Consultado em 20 de julho de 2016 de http://www.whitehutchinson.com/children/articles/nurturing.shtml . 